\title{
Uma estratégia de ensino em transportes apoiada nos perfis de personalidade dos estudantes
}

\author{
Nídia Pavan Kurii; Antônio Nélson Rodrigues da Silva²
}

\begin{abstract}
Resumo: O objetivo deste trabalho é avaliar se uma estratégia pedagógica, que visa aprimorar o processo de ensino-aprendizagem na área de Engenharia de Transportes, atingiu efetivamente todos os alunos ou se produziu resultados diferenciados em distintos perfis de personalidade. Os dados analisados resultam de três aplicações da estratégia (em 2006, 2007 e 2008) que combina Aprendizagem Baseada em Problemas com o uso de uma plataforma de ensino a distância. Na análise são consideradas: i) preferências de personalidade declaradas pelos alunos em questionário específico (Keirsey Temperament Sorter - KTS); ii) notas alcançadas nas diversas atividades desenvolvidas na plataforma on-line CoL. O desempenho dos alunos e sua comparação com os respectivos tipos de personalidade sugerem que os intuitivos, os emocionais e os perceptivos parecem ser os tipos de personalidade cujo desempenho foi mais afetado pela metodologia utilizada. O estudo sugere ainda ações corretivas que podem ser desenhadas para atender a cada um dos tipos penalizados.
\end{abstract}

\begin{abstract}
The objective of this study is to evaluate if a pedagogical approach aiming at the improvement of the teaching-learning process in the field of Transportation Engineering was equally effective for all students, in spite of their personality types. The data analyzed resulted from three applications (in 2006, 2007 and 2008) of the proposed approach, which involves the combination of PBL (Problem Based Learning) with a LMS (Learning Management System). The following data were considered: i) the personality types shown by the Keirsey Temperament Sorter (KTS); ii) the grades obtained by the students in the PBL activities developed in the on-line platform CoL. We found evidences that the performance of intuitive, emotional and perceptive students may have been affected by the pedagogic approach used. The study also suggests corrective actions that can be designed to respond to the needs of each one of the penalized personality types.
\end{abstract}

\section{INTRODUÇÃO}

Apesar da necessidade evidente de incorporar novas técnicas e habilidades aos profissionais que hoje são solicitados pelo mercado, as restrições e limitações impostas pela rígida grade curricular ainda persistem na maioria dos cursos de Engenharia Civil. Para atender a essa demanda, alguns cursos vêm passando por alterações que visam à formação de profissionais com grande capacidade de adaptação e atualização ao mercado de trabalho. Esse é o caso de alguns cursos da Escola de Engenharia de São Carlos, da Universidade de São Paulo (EESC-USP), que procuram introduzir essas alterações sem, no entanto, abrir mão do ensino dos fundamentos teóricos e das boas práticas de Engenharia. Uma maneira de atender a essa condição é se valer de alternativas pedagógicas apoiadas nas tecnologias de informática com vistas ao aprimoramento do processo de ensino-aprendizagem.

O caso analisado neste trabalho é uma alternativa aplicada a uma disciplina da área de transportes, do curso de Engenharia Civil da EESC-USP. A proposta envolve a associação do PBL (Problem Based Lear-

\footnotetext{
${ }^{1}$ Nídia Pavan Kuri, Escola de Engenharia de São Carlos, Universidade de São Paulo, São Carlos, SP, Brasil. (e-mail: nidiak@sc.usp.br).

${ }^{2}$ Antônio Nélson Rodrigues da Silva, Escola de Engenharia de São Carlos, Universidade de São Paulo, São Carlos, SP, Brasil. (e-mail: anelson@sc.usp.br).

Manuscrito recebido em 11/5/2009 e aprovado para publicação em 8/8/2010. Este artigo é parte de TRANSPORTES, volume XVIII, número 3, setembro de 2010. ISSN: 2237-1346 (online).
}

ning) a uma plataforma de ensino a distância (para mais detalhes, ver Kuri et al., 2007). Como a disciplina trata de conceitos relacionados a aspectos econômicos e sociais dos sistemas de transportes e sua influência no planejamento e operação dos mesmos, o PBL foi inserido no conteúdo programático em 2006 por meio de um problema vivenciado pelos alunos: o estacionamento no Campus. No ano de 2007, o problema estudado envolveu problemas de transporte da cidade, considerando a opinião dos usuários, segundo pesquisa de campo realizada anteriormente. Em 2008, o problema se referiu à qualidade das vias para pedestres em um trecho da cidade de São Carlos. Nos três casos o enfoque foi a realização de projetos em grupos e utilização da modalidade de ensino semipresencial.

Neste trabalho, o objetivo é avaliar se a estratégia adotada atende à maioria dos estudantes, independente de suas preferências de personalidade, ou se produz resultados diferenciados como consequência dos diferentes tipos de personalidade. A sua estrutura contempla os principais conceitos teóricos referentes ao tema proposto, a metodologia de análise adotada, uma apresentação e análise dos resultados, as conclusões sobre o estudo realizado e a bibliografia.

\section{FUNDAMENTOS TEÓRICOS}

Tendo em vista que a estratégia pedagógica aqui considerada se fundamenta em três conceitos que, embora complementares, podem ser vistos de modo autônomo, cada um deles será apresentado e brevemente discutido a seguir. 


\subsection{Aprendizagem Baseada em Problemas (Problem Based Learning - PBL)}

O conhecimento profissional, em particular na área de Engenharia, cresceu tanto que é praticamente impossível o aluno dominar todos os assuntos técnicos num período de quatro a cinco anos. Além disso, os alunos começam a ser criticados por sua falta de habilidades complementares. Sem dúvida, os cursos de Engenharia Civil asseguram graduados competentes tecnicamente, capazes de enfrentar as responsabilidades da profissão para prover serviços de qualidade à sociedade. No entanto, o desenvolvimento de outros atributos profissionais relevantes para comunicação e para trabalho em equipe, frequentemente é visto e aceito como uma responsabilidade do profissional e dependente da maturidade de cada um. Como resultado, profissionais e universitários do mundo todo buscam fortalecer as habilidades de aprender ao longo da vida, mais do que o conteúdo técnico. Assim, algumas universidades começaram a reestruturar seus cursos visando essas novas expectativas. O PBL tem se revelado um meio atrativo para tais mudanças.

O PBL é um método instrucional centrado na resolução de problemas reais. Enquanto que nos métodos "tradicionais" de ensino, primeiro são colocados os conceitos e depois os problemas ou exercícios de aplicação, no PBL acontece o contrário - as aulas se iniciam com a proposição de um problema, engajando os alunos com o conteúdo da disciplina via atividade e descoberta. O problema se constitui no ponto de partida do processo de aprendizagem e, portanto, deve ser bem formulado e suficientemente desafiador para motivar, focar, iniciar e direcionar a aprendizagem dos alunos.

De acordo com Margetson (1997), no PBL os conhecimentos não são selecionados e organizados antes, mas sim construídos durante o processo de resolução do problema. O grau de dificuldade para resolver o problema pode exigir um maior aprofundamento de conhecimentos, fato que contribui para a integração de diferentes disciplinas, consolidando o fato de que a aquisição do conhecimento independe da disciplina a que pertence.

Como no PBL o foco está no aluno e nas oportunidades de aprendizado que lhe são relevantes, os objetivos são parcialmente determinados pelos próprios estudantes. Tal característica do método não significa que o professor deva desistir de sua responsabilidade para julgar quais conteúdos e habilidades podem ser importantes para os alunos aprenderem, mas faz com que os próprios alunos tomem para si a responsabilidade parcial e explícita no que diz respeito ao seu aprendizado.

Em decorrência do uso do PBL nas mais variadas áreas educacionais, esse método instrucional tem so- frido adaptações para se adequar aos ambientes onde é implantado, razão pela qual recebe muitas definições e interpretações. Este trabalho se apóia na concepção de Howard Barrows (1986), um dos pioneiros no desenvolvimento e pesquisa do PBL, que o define como um método baseado no princípio do uso de problema como o ponto de partida para estimular a aquisição e integração de novos conhecimentos.

\subsection{Ensino semipresencial}

Diversos termos são encontrados na literatura para denominar a combinação da modalidade de educação presencial com a on-line, tais como blended learning, aprendizagem mesclada, educação semipresencial, entre outros. Conforme a definição dada pela Portaria $\mathrm{N}^{\mathrm{o}} \cdot 4059$, de 10 de dezembro de 2004, do Ministério da Educação - MEC “caracteriza-se a modalidade semipresencial como quaisquer atividades didáticas, módulos ou unidades de ensino-aprendizagem centrados na auto-aprendizagem e com a mediação de recursos didáticos organizados em diferentes suportes de informação que utilizem tecnologias de comunicação remota” (MEC, 2004).

Essa modalidade de ensino começou a ser mais utilizada após o surgimento das novas tecnologias que tornaram possível aliar, em um mesmo curso, atividades presenciais e não-presenciais. No ensino semipresencial, professor e alunos podem estar juntos, fisicamente presentes no mesmo ambiente de aprendizagem, ou distantes, mas conectados por tecnologias.

Heterick e Twigg (2003) e Garrison e Kanuka (2004) destacam o potencial do ensino semipresencial quando comparado com modelos tradicionais. Isso é evidenciado em estudos que comprovam maior satisfação dos estudantes com a modalidade semipresencial, melhoria na retenção do material estudado, no desempenho nas provas e nas atitudes dos alunos durante o processo de resolução do problema.

O que torna essa modalidade particularmente efetiva é a facilidade de formar grupos de pesquisa que proporcionem uma comunicação aberta, estável e coesa, além de disponibilizar acesso ilimitado às informações via Internet. Tais comunidades também promovem diálogos livres e debates, oportunizando a negociação e o entendimento, elementos importantes para uma boa formação profissional e pessoal. Além de potencial facilitador dessas condições, o ensino semipresencial adiciona um importante elemento reflexivo com as múltiplas formas de comunicação que proporciona.

Nesses grupos, uma parte da pesquisa pode ser feita coletivamente (juntos fisicamente) e, outras, individualmente (cada qual pesquisa no seu próprio ritmo e espaço). Ao vivo, o professor está atento às descobertas, às dúvidas, ao intercâmbio e tratamento das in- 
formações. Os estudantes pesquisam e o professor ajuda, problematiza, incentiva e relaciona. O professor coordena as trocas, os alunos relatam suas descobertas, socializam suas dúvidas, mostram os resultados de pesquisa.

Uma seleção dos melhores materiais descobertos pelos alunos, juntamente com os do professor, deve ser disponibilizada para todos, de modo que possam aprofundar a sua leitura, fazer novas sínteses, colocar os problemas que os textos suscitam e os relacionar com a sua realidade. Essa pesquisa é comunicada em classe para os colegas e o professor ajuda a contextualizar, ampliar o universo alcançado pelos alunos, problematizar, descobrir novos significados no conjunto das informações obtidas. Esse caminho de ida e volta, onde todos se envolvem e participam, é fascinante, criativo, cheio de novidades e de avanços. O conhecimento que é construído a partir da própria experiência acaba se tornando muito mais forte.

\subsection{Preferências de personalidade}

Como a missão da educação é conduzir o indivíduo a um conhecimento dinâmico do mundo, dos outros e de si mesmo, todos os aspectos relativos ao desenvolvimento de sua personalidade são importantes para melhor compreendê-lo e auxiliá-lo no processo de sua aprendizagem. Assim, o interesse do educador não deve se restringir àquilo em que o educando se parece com os demais, mas se preocupar com o que ele é e será.

Para conhecer as preferências de personalidade e de aprendizagem dos estudantes, um inventário vem sendo bastante utilizado em estudos e pesquisas acadêmicas - o Classificador de Temperamentos (Keirsey Temperament Sorter - KTS), criado por David Keirsey e Marilyn Bates para identificar os diferentes tipos de personalidade e temperamento, publicado em 1978, como parte do livro Please Understand Me (Keirsey e Bates, 1984). O KTS fornece uma estrutura para determinar as predisposições ou tendências naturais no comportamento humano. Fundamentado na teoria dos tipos psicológicos de Jung, busca determinar como as pessoas conscientemente preferem atuar no mundo, perceber, fazer julgamentos e tomar decisões. É um instrumento auto-aplicável, composto de setenta questões de escolha forçada (a ou b) que fornecem ao final um percentual para cada estilo prevalecente na dimensão da personalidade - Extroversão ou Introversão; Sensação ou Intuição; Razão ou Emoção e Julgamento ou Percepção.

Os estudantes racionais são atraídos por materiais organizados logicamente. Respondem melhor para o professor que é bem organizado, mas ressentem-se com aquele cuja organização não é lógica. Se não encontram uma ordenação lógica no material ou no pro- fessor, não conseguem direcionar suas melhores energias e esforços para as tarefas de aprendizagem. Os emocionais, quando iniciam uma nova disciplina, testam a situação com dois critérios: O professor se preocupa comigo? Vale a pena me doar para a matéria? Se uma relação de atenção com o professor e o vínculo com a matéria se estabelecem, estes tipos apresentam o seu melhor desempenho. Com ambas as condições ausentes, perdem a motivação e ajustes nas estratégias instrucionais provavelmente farão pouca diferença.

Os sensoriais respondem melhor ao funcional e prático. Seus critérios são: Este material pode me apresentar algo útil? Aprenderei algumas habilidades e farei bom uso delas? São estudantes que ficarão perdidos se o professor omitir etapas e/ou explicações, ensinar abstrações sem relacionar com a realidade ou trabalhar com material que não tem aplicação imediata. São estudantes que trabalham melhor com seus sentidos completamente engajados ("Eu penso melhor com minhas mãos...”). Os intuitivos necessitam de inspiração, porque se envolvem completamente quando a imaginação está repleta de idéias e planos intrigantes. Aborrecem-se com a rotina e, a não ser que o professor ou o material os inspirem, procuram encontrar algo que alivie o tédio e reative a chama da inspiração. Quando inspirados, são os mais inovadores de todos os tipos.

Os extrovertidos têm mais facilidade para aprender quando experiências e atividades precedem conceitos e idéias. Podem lidar eficientemente com abstrações, mas fazem melhor seu trabalho exteriormente, na ação. Têm necessidade de se comunicar, procuram grupos tanto para trabalho quanto socialização. São mais verbais que os introvertidos e isso faz com que sejam mais notados na sala de aula. Os introvertidos encontram maior facilidade para aprender quando os conceitos são explicados antes que se exijam experiências e resultados práticos. Uma vantagem dos introvertidos é a capacidade de concentração, de ignorar os estímulos exteriores que distraem e ir mais fundo no trabalho que realizam. Tendem a mostrar apenas as suas conclusões, sem detalhar o que fizeram. Essa brevidade de comunicação faz com que sejam vistos como tímidos e impenetráveis.

Os julgadores trabalham melhor quando podem planejar suas tarefas e obedecer ao que foi planejado. Estabelecem o que deve ser feito para si e também para os outros. Precisam decidir as questões e buscam o “o quê?” e o "por quê?” para chegarem à finalização. Apreciam cursos sistemáticos, tarefas definidas e trabalhos estruturados. Buscam completar os trabalhos e por isso são vistos como responsáveis e dignos de confiança. Os perceptivos são mais flexíveis, preferem atuar de modo espontâneo, buscam entender e se adaptar aos eventos. Apreciam cursos flexíveis e adap- 
táveis aos seus interesses. São considerados curiosos e pouco organizados, visto que tendem a deixar decisões em aberto, à espera de novas informações. A curiosidade pode levá-los a um extraordinário acúmulo de informações, mas não chegam à conclusão a não ser que precisem, e, às vezes nem assim.

Apresentadas as características predominantes de cada tipo, é importante destacar que a verdadeira utilidade de se conhecer o perfil de personalidade dos alunos não está em memorizar todas as peculiaridades de cada tipo, mas em entender as diferenças básicas que existem entre eles e utilizá-las de maneira construtiva.

\section{METODOLOGIA}

Este trabalho tem como foco uma análise dos resultados de três aplicações de uma estratégia pedagógica, desenvolvida na EESC-USP para o ensino de Planejamento de Transportes. A metodologia consiste, basicamente, em uma proposta de trabalho que associa o PBL com uma plataforma de ensino a distância. Os principais aspectos da proposta são:

1. Introdução do PBL como método de ensinoaprendizagem, com ênfase no trabalho de grupo;

2. Uso da plataforma de ensino a distância CoL (Cursos on-Line) desenvolvida pela Escola Politécnica da Universidade de São Paulo. O sistema fornece ferramentas dinâmicas para promover a interação entre os usuários (instrutores e estudantes) por meio de fóruns, comunicação eletrônica (e-mails e chats), e atividades colaborativas. O sistema pode ser utilizado tanto para ensino a distância quanto para a modalidade semipresencial (b-learning);

3. Adoção da modalidade de ensino semipresencial para os tópicos (1) e (2) acima descritos;

4. Complementação da abordagem "tradicional" de ensino usualmente utilizada na disciplina com as seguintes estratégias:

- Trabalho em grupo;

- Pesquisa individual e em grupo na internet;

- Uso do laboratório computacional para parte das atividades programadas na disciplina;

- Uso do Sistema de Informação Geográfica (SIG) no desenvolvimento das atividades de projeto;

5. Uso de testes, provas, relatórios dos estudantes, registros dos acessos à informação gravados pelo sistema e desempenho dos estudantes no semestre como dados para monitorar e avaliar a estratégia pedagógica utilizada;

6. Avaliação dos resultados mediante o uso de métodos quantitativos e qualitativos.
Busca-se com esta estratégia que as inovações na programação da disciplina possam trazer melhorias significativas tanto ao aprendizado, como também na postura dos futuros profissionais. A introdução dessas inovações acontece de maneira gradativa, porém sistemática, e envolve avaliações periódicas para sanar possíveis falhas observadas na abordagem adotada, como discutido em Kuri et al. (2007) e Rodrigues da Silva (2009).

Uma das estratégias de avaliação utilizadas se baseia em uma verificação do desempenho dos alunos e sua confrontação com os perfis de personalidade e com os estilos de aprendizagem. Isto visa detectar indivíduos com preferências de personalidade e de aprendizagem que, possivelmente, não são atendidos pela metodologia adotada. No caso específico deste estudo são apresentados e discutidos os resultados relacionados às preferências de personalidade.

\section{APRESENTAÇÃO E ANÁLISE DOS RESULTADOS}

Para análise dos dados, cada dimensão da personalidade foi confrontada com o desempenho dos alunos nas atividades do PBL por meio de gráficos de barras, organizados para evidenciar eventuais relações entre esses elementos. Deste modo é possível identificar a contribuição que cada dimensão pode exercer no desempenho do aluno nas atividades propostas.

Nos gráficos de barras das Figuras de 1 a 4, cada aluno corresponde a uma barra. Os alunos se encontram ordenados pelas notas, com as maiores notas à esquerda e as menores notas à direita. A altura da barra representa o perfil do aluno nas dimensões de cada caracterização e a reta vertical sobreposta ao gráfico mostra a posição da média das notas. Na análise dos dados fornecidos pelo inventário de Keirsey, optou-se por considerar os estudantes que alcançaram percentuais iguais ou superiores a $60 \%$ na dimensão da personalidade estudada, ou seja, aqueles que melhor revelaram qual o estilo predominante naquela dimensão. Os alunos com essa característica foram identificados com barras de cor mais escura nas Figuras de 1 a 4 .

Na Figura 1 observa-se que os estudantes que participaram da experiência são, na maioria, extrovertidos (ver também Tabela 1). Isso significa que ao responderem às questões do inventário, a maior parte das escolhas recaiu na alternativa indicativa da atitude extrovertida, ou seja, diante das diferentes situações colocadas, agem ou reagem preferencialmente de modo extrovertido. Dentre os extrovertidos "fortes", nota-se que a maioria apresentou aproveitamento acima da média apenas em 2007. Nos demais anos analisados (2006 e 2008), foram significativos os percentuais desses estudantes que obtiveram nota abaixo da mé- 

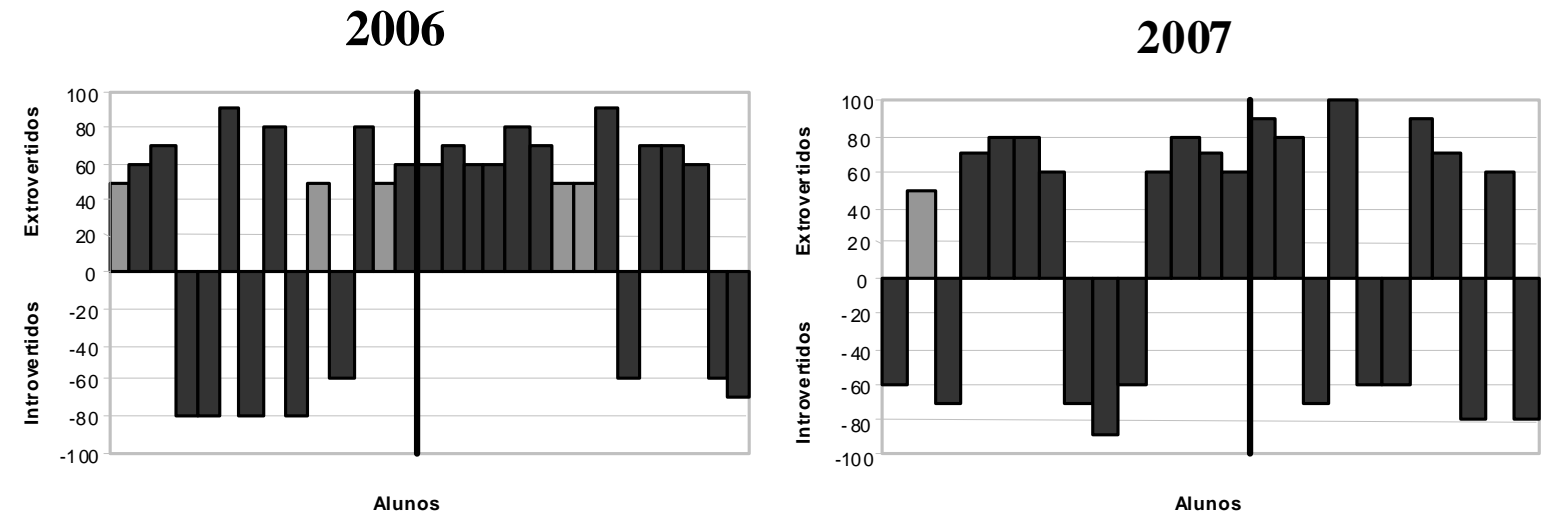

\section{8}

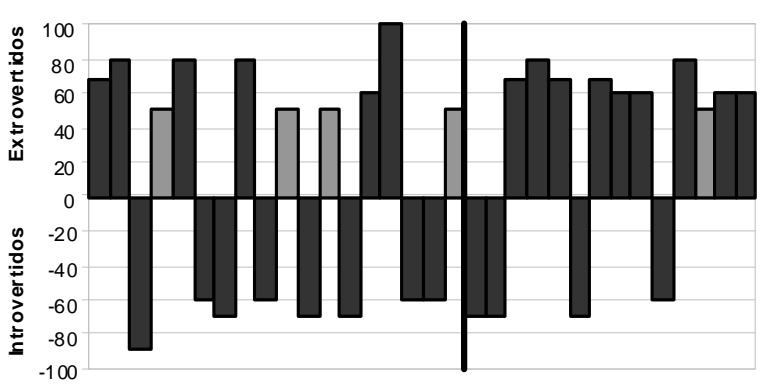

Alunos

Figura 1. Desempenho dos estudantes extrovertidos e introvertidos, por ano

Tabela 1. Desempenho acima da média - Tipos extrovertidos e tipos introvertidos "fortes" (ou seja, aqueles com percentual igual ou maior de $60 \%$ - ver Figura 1)

\begin{tabular}{|c|c|c|c|c|c|}
\hline \multirow{2}{*}{ Ano } & \multirow{2}{*}{$\begin{array}{c}N^{o} \text { Total de Alunos } \\
\text { "Fortes" } \\
\text { (igual ou maior a } 60 \% \text { ) }\end{array}$} & \multicolumn{2}{|c|}{ Extrovertidos "Fortes" } & \multicolumn{2}{|c|}{ Introvertidos “Fortes" } \\
\hline & & Acima da média & Abaixo da média & Acima da média & Abaixo da média \\
\hline 2006 & 24 (de 29) & 6 de $16=38 \%$ & 10 de $16=62 \%$ & 5 de $8=62 \%$ & 3 de $8=38 \%$ \\
\hline 2007 & 24 (de 25) & 8 de $14=57 \%$ & 6 de $14=43 \%$ & 5 de $10=50 \%$ & 5 de $10=50 \%$ \\
\hline 2008 & 27 (de 32) & 6 de $15=40 \%$ & 9 de $15=60 \%$ & 8 de $12=67 \%$ & 4 de $12=33 \%$ \\
\hline
\end{tabular}

dia. Embora em menor número, a maior parte dos introvertidos "fortes" alcançou notas acima da média nesses mesmos anos. Em 2007, observa-se que metade dos introvertidos alcançou nota acima da média e, a outra metade, nota abaixo da média.

A Figura 2 revela predominância de alunos sensoriais e maior frequência desses alunos com notas acima da média (ver também Tabela 2). Quanto aos intuitivos, observa-se nos anos de 2006 e 2008 um maior número deles com notas abaixo da média, o que sugere a necessidade de ações corretivas para esse tipo de estudante.

Na Figura 3 e na Tabela 3 verifica-se que mais da metade dos estudantes racionais "fortes" obteve notas acima da média em 2006 e 2008. Na turma de 2007, no entanto, o percentual de estudantes racionais com nota abaixo da média mostra-se superior. Os emocionais "fortes", embora em número menor que os racionais, apresentaram desempenho acima da média em 2007 e 2008. O que se constatou em 2006, por outro lado, é determinante para atenção aos tipos emocionais, pois nenhum aluno "forte" deste grupo obteve nota acima da média.

A Figura 4 e Tabela 4 mostram, no geral, uma predominância de notas acima da média dos estudantes julgadores "fortes" nos três anos analisados. Os estudantes perceptivos "fortes”, embora em número significativamente menor nos três anos avaliados, mostram

Tabela 2. Desempenho acima da média - Tipos sensoriais e tipos intuitivos "fortes" (ou seja, aqueles com percentual igual ou maior de $60 \%$ - ver Figura 2)

\begin{tabular}{|c|c|c|c|c|c|}
\hline \multirow{2}{*}{ Ano } & \multirow{2}{*}{$\begin{array}{c}N^{o} \text { Total de Alunos } \\
\text { "Fortes" } \\
\text { (igual ou maior a } 60 \% \text { ) }\end{array}$} & \multicolumn{2}{|c|}{ Sensoriais "Fortes" } & \multicolumn{2}{|c|}{ Intuitivos “Fortes" } \\
\hline & & Acima da média & Abaixo da média & Acima da média & Abaixo da média \\
\hline 2006 & 17 (de 29) & 7 de $11=64 \%$ & 4 de $11=36 \%$ & 2 de $6=33 \%$ & 4 de $6=67 \%$ \\
\hline 2007 & 16 (de 25) & 7 de $12=58 \%$ & 5 de $12=42 \%$ & 2 de $4=50 \%$ & 2 de $4=50 \%$ \\
\hline 2008 & 22 (de 32) & 8 de $13=62 \%$ & 5 de $13=38 \%$ & 4 de $9=44 \%$ & 5 de $9=56 \%$ \\
\hline
\end{tabular}


2006

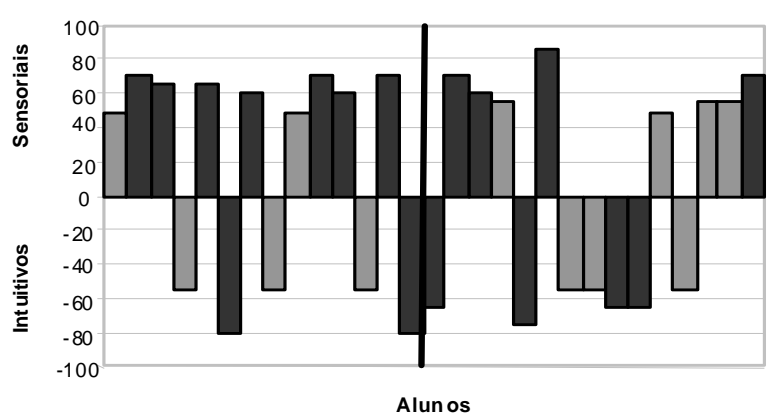

2007

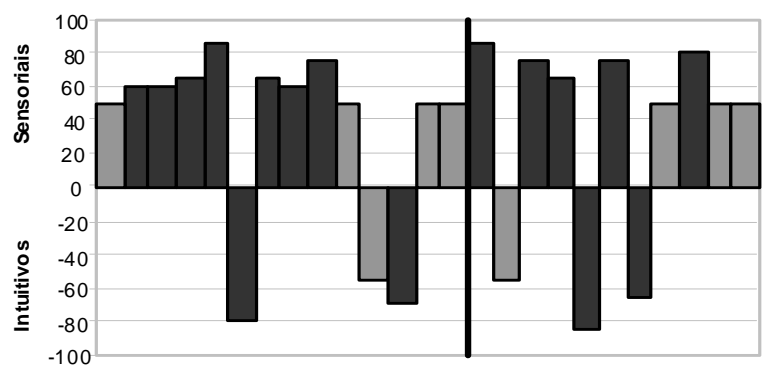

Alunos

\section{8}

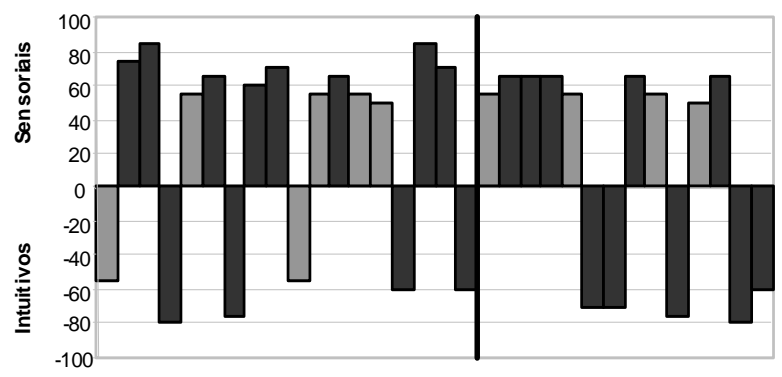

Alunos

Figura 2. Desempenho dos estudantes sensoriais e intuitivos, por ano

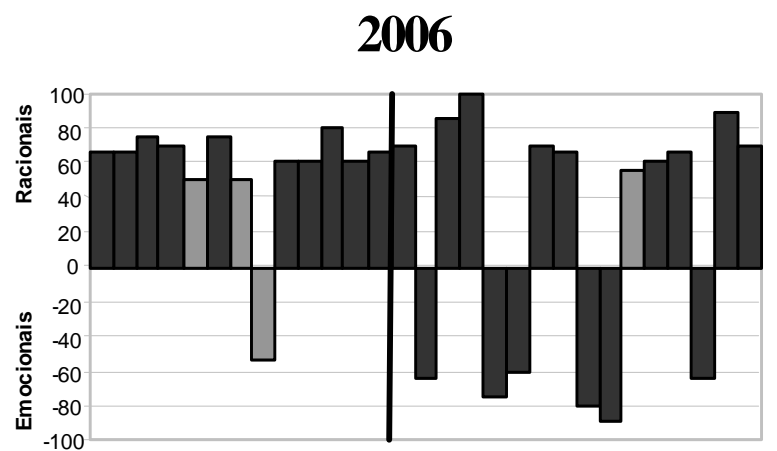

Alunos

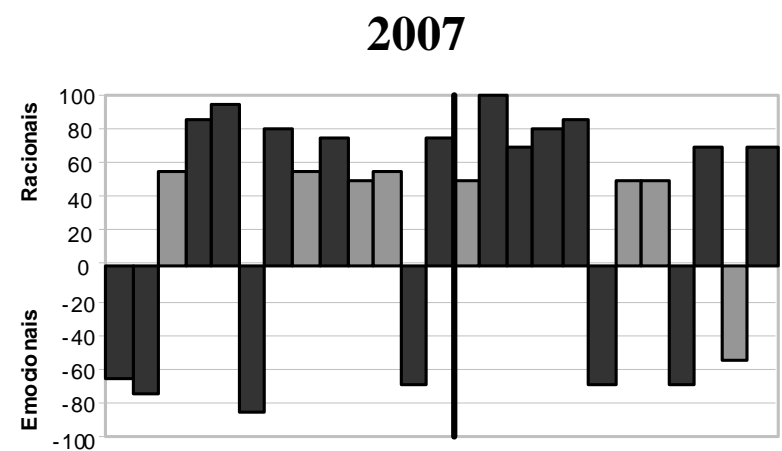

Alunos

\section{8}

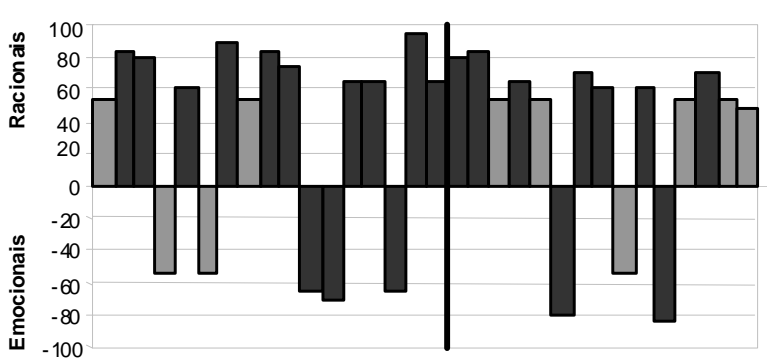

Alunos

Figura 3. Desempenho dos estudantes racionais e emocionais, por ano

Tabela 3. Desempenho acima da média - Tipos racionais e tipos emocionais "fortes" (ou seja, aqueles com percentual igual ou maior de $60 \%$ - ver Figura 3)

\begin{tabular}{|c|c|c|c|c|c|}
\hline \multirow{2}{*}{ Ano } & \multirow{2}{*}{$\begin{array}{c}N^{o} \text { Total de Alunos } \\
\text { "Fortes" } \\
\text { (igual ou maior a } 60 \% \text { ) }\end{array}$} & \multicolumn{2}{|c|}{ Racionais "Fortes" } & \multicolumn{2}{|c|}{ Emocionais “Fortes" } \\
\hline & & Acima da média & Abaixo da média & Acima da média & Abaixo da média \\
\hline 2006 & 25 (de 29) & 10 de $19=53 \%$ & 9 de $19=47 \%$ & 0 de $6=0 \%$ & 6 de $6=100 \%$ \\
\hline 2007 & 17 (de 25) & 5 de $11=45 \%$ & 6 de $11=55 \%$ & 4 de $6=67 \%$ & 2 de $6=33 \%$ \\
\hline 2008 & 22 (de 32) & 10 de $17=59 \%$ & 7 de $17=41 \%$ & 3 de $5=60 \%$ & 2 de $5=40 \%$ \\
\hline
\end{tabular}


2006

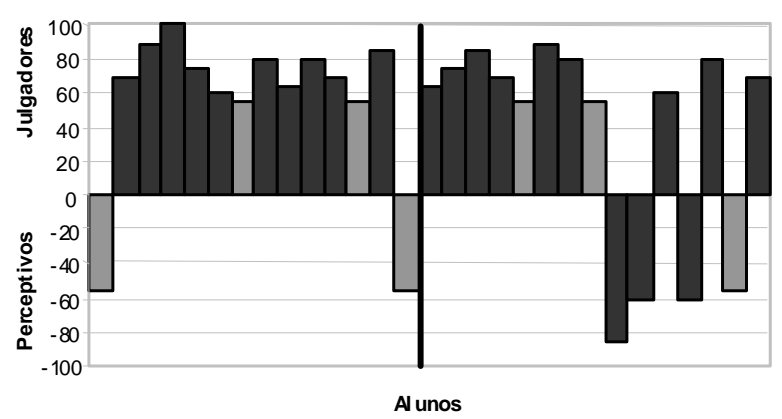

2007

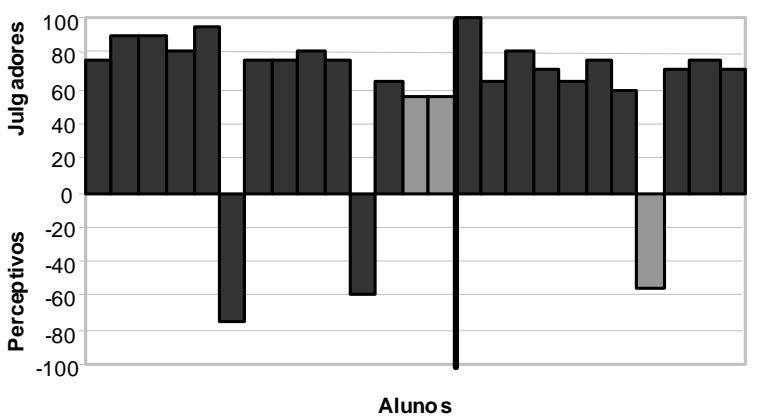

2008

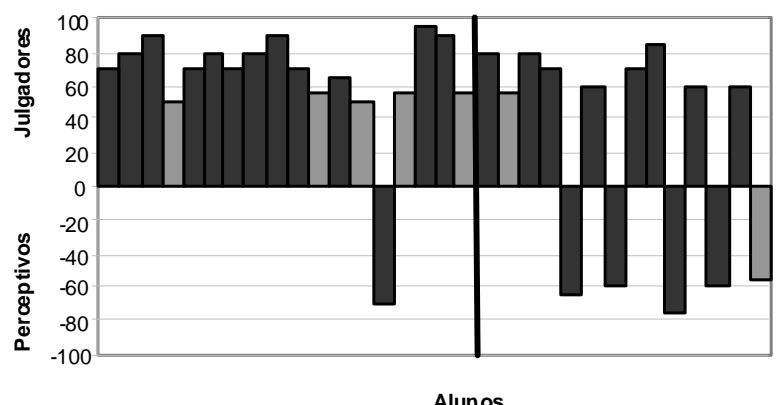

Figura 4. Desempenho dos estudantes julgadores e perceptivos, por ano

Tabela 4. Desempenho acima da média - Tipos julgadores e tipos perceptivos "fortes" (ou seja, aqueles com percentual igual ou maior de $60 \%$ - ver Figura 4)

\begin{tabular}{|c|c|c|c|c|c|}
\hline \multirow{2}{*}{ Ano } & \multirow{2}{*}{$\begin{array}{c}N^{o} \text { Total de Alunos } \\
\text { "Fortes" } \\
\text { (igual ou maior a } 60 \% \text { ) }\end{array}$} & \multicolumn{2}{|c|}{ Julgadores "Fortes" } & \multicolumn{2}{|c|}{ Perceptivos "Fortes" } \\
\hline & & Acima da média & Abaixo da média & Acima da média & Abaixo da média \\
\hline 2006 & 22 (de 29) & 10 de $19=53 \%$ & 9 de $19=47 \%$ & 0 de $3=0 \%$ & 3 de $3=100 \%$ \\
\hline 2007 & 22 (de 25) & 10 de $20=50 \%$ & 10 de $20=50 \%$ & 2 de $2=100 \%$ & 0 de $2=0 \%$ \\
\hline 2008 & 25 (de 32) & 12 de $20=60 \%$ & 8 de $20=40 \%$ & 1 de $5=20 \%$ & 4 de $5=80 \%$ \\
\hline
\end{tabular}

resultados preocupantes, uma vez que em dois dos três anos - 2006 e 2008, os percentuais desses tipos com notas abaixo da média foram de $100 \%$ e $80 \%$, respectivamente. No ano em que isso não ocorreu, o grupo de dois alunos situou-se acima da média.

\section{CONCLUSÕES}

A análise dos resultados sugere que algumas dimensões da personalidade podem ter influenciado o desempenho de tipos específicos de alunos nas atividades do PBL. Nesse caso, os extrovertidos, os intuitivos, os emocionais e os perceptivos parecem ser os tipos mais afetados pela metodologia utilizada. Visando adaptar e melhorar a estratégia, são propostas ações corretivas relacionadas a cada dimensão.

Os estudantes extrovertidos têm mais facilidade para aprender quando conceitos e idéias são precedidos por experiências e atividades. Podem lidar eficientemente com abstrações, mas fazem melhor seu trabalho exteriormente, na ação. Preferem trabalhar em grupo que sozinhos e, com frequência, apresentam os resultados de forma rápida, não dedicando tempo suficiente em um material ou situação para entenderem a idéia subjacente. Uma fraqueza típica dos estudantes extrovertidos é a tendência à superficialidade intelectual, muito forte em tipos mais extremos. A partir das observações e dos dados coletados, no entanto, não é possível identificar claramente que preferência de aprendizagem destes tipos não foi atendida pela metodologia adotada e justifica o baixo desempenho de alguns extrovertidos “fortes”. Uma eventual explicação seria a apresentação da teoria antes das atividades práticas, porém estudos adicionais são necessários para esclarecer este ponto.

A preferência por sensação/intuição indica diferenças básicas no estilo de aprendizagem. Estudantes que privilegiam a sensação, frequentemente têm a atenção voltada ao que lhes proporcionam as experiências concretas. Com seus sentidos engajados, caminham passo a passo até o entendimento da nova experiência. Os intuitivos prestam atenção ao que lhes estimula a imaginação. Aprendem holisticamente, aos saltos, buscam um padrão sempre que inspirados. Para os sensoriais, que preferem a abordagem dedutiva, a estratégia utilizada tem se mostrado eficiente, porque se inicia com problemas reais e experiências práticas. Os 
intuitivos, por sua vez, se beneficiam da abordagem indutiva, preferem a exposição teórica em primeiro lugar, seguida do detalhamento e aplicação na resolução de problemas. Muito provavelmente, para esse tipo de estudante será necessário introduzir mais oportunidades de trabalhar a teoria para estimulá-los a se engajarem nas atividades práticas.

A dimensão racional/emocional revela como os estudantes processam as informações e tomam decisões. A ênfase na análise lógica, objetiva e imparcial presente nas tarefas e responsabilidades atribuídas com o uso do PBL pode ser a causa do insucesso dos estudantes emocionais, tipos que se preocupam com a harmonia dos relacionamentos pessoais e consideram as pessoas envolvidas ao tomarem decisões. Os estudantes emocionais "fortes" podem ter sido prejudicados ao atuarem em tarefas estritamente técnicas que enfatizavam o uso de regras lógicas para ordenar os eventos, o domínio e controle intelectual das situações e a elaboração de relatórios técnicos. O desempenho exigido mostrou-se em dado momento (2006), portanto, totalmente incompatível com o perfil do emocional, tipo que valoriza o contato pessoal, a relação interpessoal harmoniosa e espera que os outros reconheçam e valorizem seus esforços pessoais.

Para beneficiar este tipo, mais oportunidades de discutir os fatores sociais e éticos envolvidos na resolução dos problemas, realização dos projetos e trabalhos que envolvem ajuda mútua e responsabilidade compartilhada, são particularmente indicadas para os estudantes emocionais. No ano de 2007 nota-se que a maioria dos estudantes racionais "fortes" não obteve nota acima da média e, provavelmente, este fato pode ser explicado pela proposta de trabalho que envolveu problemas de transporte da cidade e a opinião dos usuários, um tipo de tarefa mais indicada para o tipo emocional.

O julgamento/percepção indica como os estudantes preferem trabalhar. Os resultados alcançados pelos tipos perceptivos revelam que, muito provavelmente, a abordagem adotada para o desenvolvimento das tarefas foi incompatível com as preferências desse tipo que é mais flexível, não aprecia trabalhar com tarefas pré-determinadas, esquemas progressivos e metas a atingir. Os perceptivos foram penalizados (pelo menos em dois anos), porque não lhes foram fornecidos diferentes tipos de atividades, devendo executar as tarefas previamente definidas pelo professor. Autonomia para escolher e realizar trabalhos é uma característica forte nesses tipos, por isso o ambiente de aprendizagem deve ser mais flexível para proporcionar oportunidades para que explorem e encontrem novos fatos e possibilidades no desenvolvimento do trabalho. Discussões mais espontâneas, resolução informal de problemas, contrato individual de trabalho, tarefas que envolvem descoberta e que permitem a pesquisa em diversas fontes são atividades indicadas, pois têm potencial para motivar e envolver os perceptivos com a aprendizagem e, consequentemente, melhorar o desempenho desses tipos.

Um ponto positivo da estratégia utilizada, que envolveu a utilização do PBL em plataforma de ensino a distância, é que as alterações propostas podem ser facilmente incorporadas. Isto permitirá atender de maneira mais efetiva aos alunos cujos perfis não foram beneficiados com o novo desenho da disciplina, desde que sejam tomadas as devidas precauções para não comprometer os demais estudantes. Para avaliar tal condição, encontra-se em curso uma nova aplicação da estratégia que contempla as ações corretivas propostas.

\section{AGRADECIMENTOS}

Os autores agradecem ao $\mathrm{CNPq}$, que apoiou a realização dessa pesquisa através do Edital Universal de 2006.

\section{REFERÊNCIAS BIBLIOGRÁFICAS}

Barrows, H. S. (1986) A taxonomy of problem based learning methods. Medical Education, v. 20.

Garrison, D. R. e H. Kanuka (2004) Blended learning: Uncovering its transformative potential in higher education. The Internet and Higher Education, v. 7, n, 2, p. 95-105.

Heterick, B. e C. Twigg (2003) The learning market space. Disponível em: $<$ http://www.center.rpi.edu/LForum/LM/Feb03.html>. Acesso em: 03 out. 2007

Keirsey, D. e M. Bates (1984) Please Understand Me: Character \& Temperament Types, Prometheus Nemesis Book Company, Del Mar, CA, U.S.A.

Kuri, N. P.; G. G. Manzato e A. N. Rodrigues da Silva (2007) Aprendizado baseado em problemas em uma plataforma de ensino a distância: uma aplicação do CoL na EESC-USP. Revista Minerva, São Carlos, v. 4, n. 1

Margetson, D. (1997) Why problem-based learning is a challenge? In: Boud, D. e G. Feletti (eds.). The challenge of problem-basedlearning, London: Kogan Page.

MEC - Ministério da Educação. (2004) Portaria nº 4.059, de 10 de dezembro de 2004.

http://portal.mec.gov.br/sesu/arquivos/pdf/nova/acs_portaria4059. pdf. Acesso em: 30 jun. 2009.

Rodrigues da Silva, A. N. (2009) Aprendizado Baseado em Problemas em uma plataforma de ensino a distância: uma aplicação em engenharia. In: Kuri, N. P. e P. C. L. Segantine (eds.) Inovações no ensino: Alternativas metodológicas para melhoria da aprendizagem. São Carlos: Centro de Tecnologia Educacional para Engenharia, Escola de Engenharia de São Carlos, Universidade de São Paulo, p. 17-37. 